\title{
IMUNIDADE TRIBUTÁRIA AO CRÉDITO DE CARBONO: COM BASE NO PRINCÍPIO DA PREVENÇÃO OU PRECAUÇÃO ${ }^{1}$
}

\author{
IMMUNITY TAX ON CARBON CREDIT: BASED ON THE PRINCIPLE OF \\ PREVENTION OR PRECAUTION
}

Gabriel de Araujo Sandri²

"The question is not whether climate change is happening or not, but whether, in the face of this emergency, we ourselves can change fast enough." - Kofi Annan, 2006

SUMÁRIO: Introdução; 1 . Mecanismo de Desenvolvimento Limpo-Mdl E Crédito de Carbono; 2. Princípio da Prevenção e da Precaução; 3. Imunidade Tributária; Considerações finais; Referências das fontes citadas.

\section{RESUMO}

O aquecimento global, ocasionado pela elevação da emissão de gases de efeito estufa, é um problema transnacional que preocupa toda a humanidade. Apesar de inexistir consenso científico sobre a correlação entre a emissão antrópica de gases de efeito estufa e aquecimento global, a importância da sua redução pode ser superada com escólio nos princípios da prevenção e da precaução. Sob essas premissas, o objetivo do presente artigo é fundamentar a criação de uma imunidade tributária ao crédito de carbono, a qual resultará numa redução de custos e na consequente proliferação de projetos que visem reduzir a emissão desses gases. Quanto à Metodologia empregada, registra-se a utilização do Método Indutivo na Fase de Investigação, o Método Cartesiano na Fase de Tratamento de Dados e as considerações finais composta na base lógica

\footnotetext{
1 Artigo elaborado no âmbito dos seminários realizados na Universidade de Perugia - Itália, coordenados pelo Prof. Dr. Maurizio Oliviero, Catedrático da Faculdade de Direito da Universidade de Perugia, Professor Visitante do Exterior - PVE/CAPES na Universidade do Vale do Itajaí UNIVALI e Universidade de Brasília - UnB, com a participação do Prof. Dr. Josemar Soares e doutorandos mestres Rafael Padilha dos Santos e Jaqueline Moretti Quintero, Programa de PósGraduação Stricto Sensu em Ciência Jurídica - PPCJ/UNIVALI, cursos de Mestrado e Doutorado.

2 É Advogado, Mestrando em Ciências Jurídicas pelo CPCJ/UNIVALI e Professor de Direito Tributário, Processo Tributário e Prática de Direito Tributário na UNIVALI. E-mail: gabrielsandri@univali.br.
} 
SANDRI, Gabriel de Araujo. Imunidade tributária ao crédito de carbono: com base no princípio da prevenção ou precaução. Revista Eletrônica Direito e Política, Programa de Pós-Graduação Stricto Sensu em Ciência Jurídica da UNIVALI, Itajaí, v.10, n.4, $3^{\circ}$ quadrimestre de 2015. Disponível em: www.univali.br/direitoepolitica - ISSN 1980-7791.

Indutiva. Nas diversas fases da Pesquisa foram acionadas as Técnicas do Referente, da Categoria, do Conceito Operacional e da Pesquisa Bibliográfica.

PALAVRAS-CHAVE: Crédito de carbono; Imunidade tributária; Princípios da prevenção e precaução.

\section{ABSTRACT}

The global warming, caused by the elevation of greenhouse gases, is a transnational problem that concerns all humanity. Although inexistent scientific consensus on the correlation between the anthropogenic emissions of greenhouse gases and global warming, the importance of its reduction can be based on the principles of prevention and precaution. Under these assumptions, the objective of this article is to support the creation of a tax immunity to the carbon credit, which will result in cost savings and the consequent proliferation of projects that reduce greenhouse gas emissions. As for methodology, records the use of the inductive method for the research, the Cartesian method in data processing phase and the closing remarks made in inductive logic base. In the various stages of the research were driven techniques of the referent, the category, the operational concept and the bibliographic research.

KEYWORDS: Carbon credits; Tax immunity; Principles of prevention and precaution.

\section{INTRODUÇÃO}

Os seres humanos, indissociáveis do meio ambiente em que vivem, estão provocando, pelo incremento da sociedade industrial e pós-industrial, calcado no consumo desmedido, uma acentuada alteração na temperatura da Terra, pela elevada emissão de Gases de Efeito Estufa-GEE na atmosfera.

Contudo, o grande vilão dessa elevação de temperatura não é o efeito estufa em si, pois "sem efeito estufa, não há vida"3 importante para manter equilibrada a temperatura da terra, visto que, a exemplo das estufas (daí a sua nomenclatura), tem a função de reter na atmosfera o calor solar refletido pelo solo, evitando a sua brusca dissipação para o espaço,

\footnotetext{
${ }^{3}$ FRANGETTO, Flavia Witkowski.; GAZANI, Flavio Rufino. Viabilização jurídica do mecanismo de desenvolvimento limpo (MDL) no Brasil: o Protocolo de Kyoto e a cooperação internacional. Peirópolis: Instituto Internacional de Educação do Brasil (IIEB), 2002. p. 23.
} 
SANDRI, Gabriel de Araujo. Imunidade tributária ao crédito de carbono: com base no princípio da prevenção ou precaução. Revista Eletrônica Direito e Política, Programa de Pós-Graduação Stricto Sensu em Ciência Jurídica da UNIVALI, Itajaí, v.10, n.4, 30 quadrimestre de 2015. Disponível em: www.univali.br/direitoepolitica - ISSN 1980-7791.

reduzindo-se, por conseguinte, as extremidades de temperatura mínima e máxima, tornando-a adequada para a vida humana.

Desse modo, o ponto nodal da questão não está no efeito estufa, mas no aumento da concentração de gases que provocam esse efeito $\left(\mathrm{CO}_{2}, \mathrm{CFC}, \mathrm{CH}_{4}\right.$, $\mathrm{N}_{2} \mathrm{O}, \mathrm{SF}_{6}$ etc.), quase sempre provocados pela intervenção humana na natureza, mormente pelo advento da produção industrial, que trouxe a reboque a queima de combustíveis fósseis (petróleo, gás natural e carvão), a produção animal (gado, aves, suínos etc.) em larga escala, aterros sanitários etc.

Como é consabido, com o aumento da temperatura terrestre advêm sérias e catastróficas consequências: alteração radical do modo de vida hodierno e das estruturas econômicas já concebidas, as quais já são extremamente sensíveis às pequenas variações do clima; alteração da própria paisagem da terra, com o desaparecimento de ilhas e o avanço das águas marítimas; o aumento de catástrofes ambientais e as nefastas consequências de si oriundas; a emigração e assentamento de populações litorâneas para os locais de maiores altitudes; a redução de áreas para o cultivo de alimentos e a desertificação do solo; a escassez de água potável etc.

Diante dessas circunstâncias, torna-se necessário engendrar um freio capaz de evitar - ou ao menos retardar - a eclosão desses efeitos, combatendo-se a sua causa, isto é, combatendo-se a emissão de GEE, apesar das grandes complexidades práticas envolvidas nessa operação, mormente com relação ao modus operandi de "como fazer"".

Nesse panorama - embora a preocupação advenha desde longa data, principalmente desde o Relatório de Brundtland, apresentado em 1987, mas com origens fincadas desde a Conferência de Estocolmo, de 1972 - o debate sobre o

\footnotetext{
${ }^{4}$ L'intera questione del cambiamento climatico può essere riassunta in pochi aspetti essenziali. Le emissioni di gas serra sono eccessive. Devono essere ridotte. Come farlo? La questione diventa però rapidamente più complessa quando si iniziano a considerare gli aspetti pratici. Che cosa deve essere fatto in concreto, da chi, chi deve prendere quali decisioni e soprattutto: a chi spetta finanziare le misure necessarie? (PANI. Gianguido. Il Protocollo di Kyoto adempimento e sviluppi futuri: normativa strategie tecnologie. San Lazzaro di Savena (Bologna): Zanichelli, 2008. p. 589).
} 
SANDRI, Gabriel de Araujo. Imunidade tributária ao crédito de carbono: com base no princípio da prevenção ou precaução. Revista Eletrônica Direito e Política, Programa de Pós-Graduação Stricto Sensu em Ciência Jurídica da UNIVALI, Itajaí, v.10, n.4, $3^{\circ}$ quadrimestre de 2015. Disponível em: www.univali.br/direitoepolitica - ISSN 1980-7791.

tema começou a ganhar corpo internacional com a Convenção-Quadro das Nações Unidas sobre Mudança do Clima.

A Convenção-Quadro das Nações Unidas sobre Mudança do Clima-UNFCCC ${ }^{5}$, também conhecida como Convenção do Clima ou Convenção do Rio ${ }^{6}$, teve seu texto adotado na sede da ONU, em Nova York, no dia 09 de maio de 1992. A Convenção esteve aberta a assinaturas no Rio de Janeiro, de 4 a 14 de junho de 1992, durante a Conferência das Nações Unidas sobre Meio Ambiente e Desenvolvimento - apelidada de Rio-92, Eco-92 ou Rio Earth Summit - e posteriormente na sede da ONU, de 20 de junho de 1992 a 9 de junho de 19937, reunindo mais de cem chefes de Estado na busca de uma abordagem equilibrada e integrada das questões relativas ao meio ambiente e desenvolvimento. Até aquela data, a Convenção-Quadro já havia recebido 166 adesões.

No entanto, não obstante a preocupação fosse premente, ainda não se havia estabelecido limites de emissão de GEE, nem se estabelecera, por conseguinte, disposições coercitivas àqueles que as desrespeitassem.

Foi somente na terceira Conferência das Partes do UNFCCC, realizada em 1997, em Quito, Japão, que ficou estabelecido, no documento alcunhado de Protocolo de Quioto, com base no "princípio das responsabilidades comuns, porém diferenciadas $^{\prime 8}$, os limites para a emissão de GEE pelos países que historicamente mais o emitiram, denominados, pelo referido documento, de países (Partes) Anexo I.

\footnotetext{
${ }^{5}$ United Nations Framework Convention on Climate Change, em inglês.

${ }^{6}$ Rio Convention, em inglês.

7 UNFCC. Status of Ratification. Disponível em <http://unfccc.int/essential_background/ convention/status_of_ratification/items/2631.php>. Acesso em 22 dez. 2014.

8 Cf. LIMIRO, Danielle. Créditos de carbono: Protocolo de Kyoto e projetos de MDL. Curitiba: Juruá, 2009. p. 55: "O princípio das 'responsabilidades comuns, mas diferenciadas', foi estabelecido depois de observados que a maior parcela das emissões globais, históricas e atuais, de gases de efeito estufa é originária dos países desenvolvidos, pois as emissões per capita dos países em desenvolvimento ainda são relativamente baixas".
} 
SANDRI, Gabriel de Araujo. Imunidade tributária ao crédito de carbono: com base no princípio da prevenção ou precaução. Revista Eletrônica Direito e Política, Programa de Pós-Graduação Stricto Sensu em Ciência Jurídica da UNIVALI, Itajaí, v.10, n.4, $3^{\circ}$ quadrimestre de 2015. Disponível em: www.univali.br/direitoepolitica - ISSN 1980-7791.

A meta para as Partes Anexo I ficou inicialmente definida pela redução de suas emissões totais de GEE em pelo menos $5 \%$ (cinco por cento) abaixo dos níveis de 1990 no período de compromisso de 2008 a $2012^{9}$.

Para auxiliar as Partes Anexo I a cumprirem com as metas traçadas para a redução da emissão de GEE, ficaram estabelecidos alguns Mecanismos de Flexibilização ${ }^{10}$ : Implementação Conjunta; Comércio de Emissões; e Mecanismos de Desenvolvimento Limpo.

Como o presente trabalho tem o apequenado e despretensioso objetivo de fundamentar a criação de uma imunidade tributária ao crédito de carbono, com base no princípio da prevenção e precaução, o estudo sobre os Mecanismos da Implementação Conjunta e do Comércio de Emissões escapa ao foco do estudo, porquanto se tratarem de institutos que afetam diretamente tão-somente as Partes Anexo I, o que não é o caso do Brasil (Não-Anexo I).

\section{MECANismo de Desenvolvimento Limpo-MDL e CRÉdito DE CARBONO}

De início, tem-se que a expressão "crédito de carbono" não representa, fidedignamente, a verdadeira abrangência do instituto, porque não abrange somente a redução do dióxido de carbono, mas de todos os GEE.

A nomenclatura técnica para o "crédito de carbono", dada pelo Protocolo de Quito, é Redução Certificada de Emissões (art. 12, §30., alínea "a", do

\footnotetext{
${ }^{9}$ Art. 30., $1^{\circ}{ }^{\circ}$, do Protocolo de Quito, promulgado pelo Decreto no. 5.445/05. Disponível em: <http://www.planalto.gov.br/ccivil_03/_Ato2004-2006/2005/Decreto/D5445.htm>. Acesso em 22 dez. 2014.

${ }^{10}$ Dispõe o art. $2^{\circ}$., $\S 3^{\circ}$., do Protocolo de Quito, promulgado pelo Decreto no. 5.445/05: "As Partes incluídas no Anexo I devem empenhar-se em implementar políticas e medidas a que se refere este Artigo de forma a minimizar efeitos adversos, incluindo os efeitos adversos da mudança do clima, os efeitos sobre o comércio internacional e os impactos sociais, ambientais e econômicos sobre outras Partes, especialmente as Partes países em desenvolvimento e em particular as identificadas no Artigo 4, parágrafos 8 e 9, da Convenção, levando em conta o Artigo 3 da Convenção. A Conferência das Partes na qualidade de reunião das Partes deste Protocolo pode realizar ações adicionais, conforme o caso, para promover a implementação das disposições deste parágrafo". Disponível em: <http://www.planalto.gov.br/ccivil_03/_Ato20042006/2005/Decreto/D5445.htm>. Acesso em 22 dez. 2014.
} 
SANDRI, Gabriel de Araujo. Imunidade tributária ao crédito de carbono: com base no princípio da prevenção ou precaução. Revista Eletrônica Direito e Política, Programa de Pós-Graduação Stricto Sensu em Ciência Jurídica da UNIVALI, Itajaí, v.10, n.4, 30 quadrimestre de 2015. Disponível em: www.univali.br/direitoepolitica - ISSN 1980-7791.

Protocolo), a qual poderia ser complementada, para melhor compreensão, como sendo Redução Certificada de Emissões de Gases de Efeito Estufa. Poder-se-ia, também, numa simples adaptação do termo amplamente adotado (crédito de carbono), chamá-lo de "crédito de gases de efeito estufa".

Contudo, é bastante compreensível a adoção do referido termo, mormente porque todos esses GEE, para o efeito de obtenção de "crédito", são medidos, por padronização, em toneladas equivalentes de dióxido de carbono $\left(\mathrm{tCO}_{2} \mathrm{e}\right.$ ou $\left.\mathrm{tCO}_{2} \mathrm{eq}\right)^{11}$.

Sobre o tema, tem-se que a normatização do MDL se encontra incrustada, em detalhes, no artigo 12, do Protocolo de Quioto:

1. Fica definido um mecanismo de desenvolvimento limpo.

2. O objetivo do mecanismo de desenvolvimento limpo deve ser assistir às Partes não incluídas no Anexo I para que atinjam o desenvolvimento sustentável e contribuam para o objetivo final da Convenção, e assistir às Partes incluídas no Anexo I para que cumpram seus compromissos quantificados de limitação e redução de emissões, assumidos no Artigo 3.

3. Sob o mecanismo de desenvolvimento limpo:

(a) As Partes não incluídas no Anexo I beneficiar-se-ão de atividades de projetos que resultem em reduções certificadas de emissões; e

(b) As Partes incluídas no Anexo I podem utilizar as reduções certificadas de emissões, resultantes de tais atividades de projetos, para contribuir com o cumprimento de parte de seus compromissos quantificados de limitação e redução de emissões, assumidos no Artigo 3, como determinado pela Conferência das Partes na qualidade de reunião das Partes deste Protocolo.

4. O mecanismo de desenvolvimento limpo deve sujeitar-se à autoridade e orientação da Conferência das Partes na qualidade de reunião das Partes deste Protocolo e à supervisão de um conselho executivo do mecanismo de desenvolvimento limpo.

\footnotetext{
${ }^{11}$ A tabela com a equivalência dos demais GEE com relação ao gás carbono pode ser encontrada no endereço eletrônico oficial da UNFCC, no seguinte link: <http://unfccc.int/ghg_data/items/3825.php>. Acesso em 23 dez. 2014.
} 
SANDRI, Gabriel de Araujo. Imunidade tributária ao crédito de carbono: com base no princípio da prevenção ou precaução. Revista Eletrônica Direito e Política, Programa de Pós-Graduação Stricto Sensu em Ciência Jurídica da UNIVALI, Itajaí, v.10, n.4, $3^{\circ}$ quadrimestre de 2015. Disponível em: www.univali.br/direitoepolitica - ISSN 1980-7791.

5. As reduções de emissões resultantes de cada atividade de projeto devem ser certificadas por entidades operacionais a serem designadas pela Conferência das Partes na qualidade de reunião das Partes deste Protocolo, com base em:

(a) Participação voluntária aprovada por cada Parte envolvida;

(b) Benefícios reais, mensuráveis e de longo prazo relacionados com a mitigação da mudança do clima, e

(c) Reduções de emissões que sejam adicionais às que ocorreriam na ausência da atividade certificada de projeto.

6. O mecanismo de desenvolvimento limpo deve prestar assistência quanto à obtenção de fundos para atividades certificadas de projetos quando necessário.

7. A Conferência das Partes na qualidade de reunião das Partes deste Protocolo deve, em sua primeira sessão, elaborar modalidades e procedimentos com o objetivo de assegurar transparência, eficiência e prestação de contas das atividades de projetos por meio de auditorias e verificações independentes.

8. A Conferência das Partes na qualidade de reunião das Partes deste Protocolo deve assegurar que uma fração dos fundos advindos de atividades de projetos certificadas seja utilizada para cobrir despesas administrativas, assim como assistir às Partes países em desenvolvimento que sejam particularmente vulneráveis aos efeitos adversos da mudança do clima para fazer face aos custos de adaptação.

9. A participação no mecanismo de desenvolvimento limpo, inclusive nas atividades mencionadas no parágrafo 3(a) acima e na aquisição de reduções certificadas de emissão, pode envolver entidades privadas e/ou públicas e deve sujeitar-se a qualquer orientação que possa ser dada pelo conselho executivo do mecanismo de desenvolvimento limpo.

10. Reduções certificadas de emissões obtidas durante o período do ano 2000 até o início do primeiro período de compromisso podem ser utilizadas para auxiliar no cumprimento das responsabilidades relativas ao primeiro período de compromisso.

Em rápidas linhas, poder-se-ia afirmar que o MDL é uma forma subsidiária $^{12}$ que as Partes Anexo I têm para cumprir com as metas

\footnotetext{
12 Diz-se subsidiária porque as Partes Anexo I não podem cumprir com suas quotas de redução tão-somente com base na compra de Reduções Certificadas de Emissões, conforme definido pela Decisão 15, da COP7, em Marraqueche: "1. Decides that the use of the mechanisms shall be supplemental to domestic action and that domestic action shall thus constitute a significant
} 
SANDRI, Gabriel de Araujo. Imunidade tributária ao crédito de carbono: com base no princípio da prevenção ou precaução. Revista Eletrônica Direito e Política, Programa de Pós-Graduação Stricto Sensu em Ciência Jurídica da UNIVALI, Itajaí, v.10, n.4, $3^{\circ}$ quadrimestre de 2015. Disponível em: www.univali.br/direitoepolitica - ISSN 1980-7791.

estabelecidas, mediante a compra de Reduções Certificadas de Emissões (os Créditos de Carbono) produzidos por projetos realizados em países em desenvolvimento Não-Anexo I, isto é, em países que ainda não possuem metas de redução de GEE fixadas pelo Protocolo ${ }^{13}$.

A título de curiosidade, convém mencionar que a criação do MDL pelo Protocolo de Quioto é fruto de uma proposta brasileira (Brazilian Proposal) apresentada em 28 de maio de 1997 - ou seja, antes da Conferência em Quito -, a qual serviu como a linha mestra para a criação do MDL, possibilitando que os países NãoAnexo I também pudessem contribuir para a redução das emissões de GEE, remunerando-se por esse "serviço", além de definir metas diferenciadas de redução de emissões para as Partes, na proporção de suas emissões históricas de GEE.

Em que pese o MDL seja um instituto que visa distribuir a riqueza entre as nações que precisam cumprir com as suas metas de reduções e aquelas que, embora ainda não precisem formalmente reduzi-las, podem fazer essa redução com um menor custo, mesmo assim os projetos de MDL, no Brasil, possuem um valor elevado de implementação, muito em razão da acentuada burocracia que o envolve, além da correspondente incidência tributária sobre essas atividades.

Danielle Limiro $^{14}$, em seus estudos, afirma que os custos das etapas de um projeto de MDL podem variar, a depender da magnitude e complexidade, de 60 (sessenta) a 205 (duzentos e cinco) mil dólares americanos!

É justamente visando reduzir esse elevado custo, que de certa forma ilide a realização de vários pequenos projetos, que se passará a apresentar a importância da criação de benefícios tributários àqueles que se lançam a concretizar tais projetos, pois, com a redução dos custos tributários incidentes,

element of the effort made by each Party included in Annex I to meet its quantified emission limitation and reduction commitments under Article 3, paragraph $1^{\prime \prime}$. Disponível em: <http://unfccc.int/resource/docs/cop7/ 13a02.pdf\#page=2> Acesso em 26 dez. 2014.

13 SISTER, Gabriel. Mercado de carbono e Protocolo de Quioto: aspectos negociais e tributação. Rio de Janeiro: Elsevier, 2008. p. 13.

${ }^{14}$ LIMIRO, Danielle. Créditos de carbono: Protocolo de Kyoto e projetos de MDL. p. 120. 
SANDRI, Gabriel de Araujo. Imunidade tributária ao crédito de carbono: com base no princípio da prevenção ou precaução. Revista Eletrônica Direito e Política, Programa de Pós-Graduação Stricto Sensu em Ciência Jurídica da UNIVALI, Itajaí, v.10, n.4, $3^{\circ}$ quadrimestre de 2015. Disponível em: www.univali.br/direitoepolitica - ISSN 1980-7791.

possibilitará uma maior proliferação deles, culminando numa menor emissão de GEE no planeta.

Mas antes, porquanto atrelado ao tema, passar-se-á a demonstrar a importância dos princípios da prevenção e da precaução para a fundamentação da desoneração tributária a que se propõe.

\section{PRINCÍPIO dA PREVENÇÃo E dA PRECAUÇÃo}

De início, convém mencionar que os princípios de Direito Ambiental possuem seu nascedouro positivista na Conferência da Organização das Nações Unidas sobre o Meio Ambiente Humano, realizada em Estocolmo, na Suécia, em 16 de junho de 1972, que foi um dos principais marcos regulatórios (se é que chega a ser qualificado desse modo) e uma das primeiras oportunidades internacionais de debate sobre o meio ambiente e ação humana.

Com efeito, os princípios da prevenção e da precaução estão intimamente relacionados à sociedade de risco desnudida por Ulrich Beck $^{15}$, na qual a humanidade, em razão da magnitude dos riscos que ela mesma se impõe, não tem mais a capacidade de prever e "profetizar cientificamente" todos os efeitos de suas condutas no meio ambiente, impossibilitando uma pronta reação.

Para o Direito Ambiental Italiano, na esteira de Domenico Amirante:

Il princìpio della "prevenzione" è un tipico princìpio "orizzontale" del diritto ambientale, in quanto l'approccio preventivo va applicato a tutti gli interventi ambientali ed è volto a ridurre al minimo, anzi potenzialmente ad azzerare, la necessità di interventi "a valle", cioè successivi alla produzione del danno

\footnotetext{
15 Tem-se por sociedade de risco aquela que gera consequências cuja limitação temporal, espacial e social se torna impossível de ser prevista, em razão da transnacionalidade dos danos causáveis. Cf. BECK, Ulrich. Liberdade ou capitalismo: Ulrich Beck conversa com Johannes Willms. Trad. Luiz Antôno Oliveira de Araújo.São Paulo: Editora UNESP, 2003. p. 120: "a saber, que a sociedade de risco mais antiga, ou seja, a sociedade do risco da Primeira Modernidade, que partia do princípio de que o risco e suas conseqüências eram localizáveis, afetavam um círculo limitado de pessoas e um lugar limitado e, por isso mesmo, podia ser tecnicamente superado, essa experiência levou a um bloqueio mental. Ninguém podia imaginar que uma Modernidade que se moderniza gera riscos tão diferentes, riscos das dimensões de Chernobil". Sobre o assunto, vide também: BECK, Ulrich. Sociedade de risco: rumo a uma outra modernidade. Tradução de Sebastião Nascimento; inclui entrevista inédita com o autor. São Paulo: 34, 2010. p.85.
} 
SANDRI, Gabriel de Araujo. Imunidade tributária ao crédito de carbono: com base no princípio da prevenção ou precaução. Revista Eletrônica Direito e Política, Programa de Pós-Graduação Stricto Sensu em Ciência Jurídica da UNIVALI, Itajaí, v.10, n.4, $3^{\circ}$ quadrimestre de 2015. Disponível em: www.univali.br/direitoepolitica - ISSN 1980-7791.

all'ambiente. [...] il principio precauzionale, introdotto nell'art $130 \mathrm{R}$ dal Trattato di Maastricht, nel 1992. Concettualmente si tratta di un principio assai diverso da quello preventivo, in quanto si ricollega in particolare alla questione dei rischi ambientali ed è il risultato di una profonda riconsiderazione dei rapporti fra diritto e scienza, passibile di influenzare in modo rilevante la stessa "filosofia" degli interventi di tutela ambientale. ${ }^{16}$

Desse modo, exsurge a necessidade de se prevenir dos riscos provenientes de causas conhecidas (prevenção), e de se precaver daqueles com causas (e efeitos) ainda não-cientificamente comprovados (precaução), porém de existência possível.

Por sua vez, Giovanni Cordini ${ }^{17}$ faz uma ligação desses princípios com a necessidade de proteção das presentes e futuras gerações, em semelhança ao que a Constituição da República Federativa do Brasil de 1988 traz em seu artigo 225:

In alcuni recenti testi costituzionali e legislativi si fa riferimento alla protezione dell'ambiente per indurre gli uomini del nostro tempo ad assume una responsabilità giuridica anche nei confronti delle future generazioni. Il fondamento sul quale poggia questa affermazione di principio è la percezione che i beni della Terra sono limitati ed esauribili. Sul piano teorico si tratta di un'avvertenza che nell'opinione pubblica contemporanea sembra largamente acquista. Di conseguenza, nel patto costituzionale, l'integritá dell'ambiente, è indicata come uno scopo primario per l'esistenza e lo sviluppo della comunità umana.

16 AMIRANTE, Domenico. Ambiente e principi costituzionali nel diritto comparato. In: AMIRANTE, Domenico (a cura di). Diritto ambientale e costituzione: esperienze europee. Milano: FrancoAngeli, 2010. p. 38-40. Tradução livre: O princípio da "prevenção" é um típico princípio "horizontal" de direito ambiental, enquanto a abordagem preventiva deve ser aplicada a todas as intervenções ambientais e destina-se a reduzir, potencialmente a zero, a necessidade de uma ação "a jusante" (constante), isto é, é próximo à (fonte) produtora dos danos ambientais. [...] 0 princípio da precaução, introduzido no artigo 130R do Tratado de Maastricht em 1992. Conceitualmente, é um princípio muito diferente do princípio da prevenção, no que se refere, particularmente, à questão dos riscos ambientais e do resultado de uma profunda reconsideração da relação entre direito e ciência, suscetíveis de afetar significativamente a mesma "filosofia" das intervenções da tutela ambiental.

17 CORDINI, Giovanni. Dirrito ambientale comparato. 3. ed. Milani: CEDAM, 2002. p. 27. Tradução livre: Em alguns recentes textos constitucionais e legais se faz referimento à proteção do ambiente para induzir os homens de nosso tempo a assumir uma responsabilidade jurídica também com as futuras gerações. O fundamento sobre o qual se apóia a afirmação desse princípio é a percepção de que os bens da terra são limitados e exauríveis. No plano teórico, é um aviso de que a opinião pública contemporânea parece largamente aderir. Por conseguinte, no pacto constitucional, a integridade do meio ambiente é indicada como um objetivo principal para a existência e desenvolvimento da comunidade humana. 
SANDRI, Gabriel de Araujo. Imunidade tributária ao crédito de carbono: com base no princípio da prevenção ou precaução. Revista Eletrônica Direito e Política, Programa de Pós-Graduação Stricto Sensu em Ciência Jurídica da UNIVALI, Itajaí, v.10, n.4, $3^{\circ}$ quadrimestre de 2015. Disponível em: www.univali.br/direitoepolitica - ISSN 1980-7791.

Contudo, a diferenciação teórica entre os dois princípios é bem sentida por Luca Nivarra ${ }^{18}$, quando afirma que:

La commistione dei piani precauzionale e cautelare à spesso presente nella giurisprudenza e nasce dalla similitudine e dalla contiguità dei due criteri, ma non è condivisibile e non aiuta a comprendere il carattere innovativo del Pdp [Principio di precauzione]. La diversità dei momenti va condivisa, perché differenti sono la natura giuridica e la funzione dei due livelli di intervento (precauzionale e cautelare). Il Pdp, lo si è detto, si muove dentro una cornice di "incertezza", in ragione della mancanza o non univocità di dati in ordine alla innocuità del bene o dell'attività. Il concetto di prevenzione che funge da presupposto per l'adozione di misure cautelative, viceversa, si base sulla chiara percezione della portata del rischio, la cui conoscenza costituisce la base stessa per la previsione di idonee misure volte a prevenire il suo concretizzarsi in una dimensione di danno. L'idea che il Pdp sia frutto de un'esigenza di prevenzione, per quanto fuorviante, mette in risalto un aspetto rilevante del metodo precauzionale e mostra come il problema attenga alla necessità di impedire il concretizzarsi di un danno temuto. Questo elemento, inserito in un contesto di incertezza (scientifica), però, fa si che non si possa sovrapporre il concetto di precauzione con quello di prevenzione.

No mesmo viés, tem-se que a pedra fundamental do princípio da precaução vem insculpida no Princípio 15, da Declaração do Rio/92:

Com o fim de proteger o meio ambiente, o princípio da precaução deverá ser amplamente observado pelos Estados, de acordo com suas capacidades. Quando houver ameaça de danos graves ou irreversíveis, a ausência de certeza científica absoluta não será

\footnotetext{
18 NIVARRA, Luca. Azione inibitoria e principio di precauzione. In: D'ADDA, Alessandro; NICOTRA, Ida Angela; SALANITRO, Ugo (a cura di). Principi europei e illecito ambientale. Torino: G. Giappichelli, 2013. p. 198. Tradução livre: A confusão entre os princípios da precaução e da prevenção, muitas vezes presentes na jurisprudência, nasce da similitude e da contiguidade dos dois critérios, mas não é compartilhável e não ajuda a compreender a natureza inovadora do princípio da precaução. A diversidade de momentos para ser compartilhado, porque são diferentes a natureza jurídica e a função dos dois níveis de intervenção (da precaução e de prevenção). O princípio da precaução, como se diz, move-se em um quadro de "incerteza", por causa da falta ou não-singularidade de dados quanto à inocuidade do bem ou atividade. $O$ conceito de prevenção, que serve como um pré-requisito para a adoção de medidas cautelares, por outro lado, baseia-se na clara percepção da dimensão do risco, cujo conhecimento constitui a própria base para a previsão de medidas adequadas para impedir a sua materialização em uma dimensão danos. A idéia de que o PDP é o resultado de uma necessidade de prevenção, porquanto enganosa, destaca um aspecto importante do método de precaução e mostra como o problema atende à necessidade de impedir a ocorrência de um dano temido. Este elemento, inserido em um contexto de incerteza (científica) faz, no entanto, que não se possa sobrepor o conceito de precaução com o da prevenção.
} 
SANDRI, Gabriel de Araujo. Imunidade tributária ao crédito de carbono: com base no princípio da prevenção ou precaução. Revista Eletrônica Direito e Política, Programa de Pós-Graduação Stricto Sensu em Ciência Jurídica da UNIVALI, Itajaí, v.10, n.4, $3^{\circ}$ quadrimestre de 2015. Disponível em: www.univali.br/direitoepolitica - ISSN 1980-7791.

utilizada como razão para o adiamento de medidas economicamente viáveis para prevenir a degradação ambiental. ${ }^{19}$

Nota-se, de pronto, que o mencionado princípio espraia observância mesmo que haja um simples receio de que uma determinada ação humana possa causar danos graves ou irreversíveis, ainda que o nexo de causalidade entre ambos (ação e dano) não tenha nem sequer sido comprovado cientificamente.

Desse modo, é preferível, pelo princípio em tela, que se evite (precavendo-se) ou ao menos que se mitigue - a realização da conduta potencialmente lesiva ao meio ambiente, a despeito de inexistir estudos (dito) científicos (empíricoindutivos) que estabeleçam uma correlação danosa, do que, ao invés, tolerá-la (a conduta) porque ainda não se tem provas que os danos, de fato, exsurgirão na escala prevista. É a própria adoção do aforismo de que "prevenir é melhor do que remediar".

Entretanto, conforme bem ressaltado por Paulo Affonso Leme Machado ${ }^{20}$,

a implementação do princípio da precaução não tem por finalidade imobilizar as atividades humanas. Não se trata da precaução que tudo impede ou que em tudo vê catástrofes ou males. O princípio da precaução visa à durabilidade da sadia qualidade de vida das gerações humanas e à continuidade da natureza existente no planeta.

Logo, o indigitado princípio deve ser aplicado com parcimônia, pois não se pode impedir todo e qualquer empreendimento pela leviana alegação de que poderá causar um dano ambiental grave e irreversível, cujos danos não têm o menor indício de causalidade com a ação empreendida. Assim, para que se possa implementar - e observar - o decantado princípio, a Carta Política de 1988 prevê, em seu art. $225, \S 1^{\circ}$. , inc. $V$, que para assegurar a efetividade do direito ao meio ambiente ecologicamente equilibrado, incumbe ao Poder Público "controlar a produção, a comercialização e o emprego de técnicas, métodos e substâncias que comportem risco para a vida, a qualidade de vida e o meio

19 ONU. Declaração do Rio sobre Meio Ambiente e Desenvolvimento. Disponível em: <http://www.onu.org.br/rio20/img/2012/01/rio92.pdf>. Acesso em 22 dez. 2014.

20 MACHADO, Paulo Affonso Leme apud PADILHA, Norma Sueli. Fundamentos constitucionais do direito ambiental. Rio de Janeiro: Elsevier, 2010. p. 66. 
SANDRI, Gabriel de Araujo. Imunidade tributária ao crédito de carbono: com base no princípio da prevenção ou precaução. Revista Eletrônica Direito e Política, Programa de Pós-Graduação Stricto Sensu em Ciência Jurídica da UNIVALI, Itajaí, v.10, n.4, 30 quadrimestre de 2015. Disponível em: www.univali.br/direitoepolitica - ISSN 1980-7791.

ambiente". Esse controle é, atualmente, partilhado pelos membros integrantes do Sistema Nacional do Meio Ambiente - SISNAMA.

Numa linha protetiva um pouco mais robusta, ergue-se o princípio da prevenção, o qual também possui previsão na Declaração de Princípios do Rio, precisamente em seu Princípio 17, ao dispor que "a avaliação do impacto ambiental, como instrumento nacional, será efetuada para as atividades planejadas que possam vir a ter um impacto adverso significativo sobre o meio ambiente e estejam sujeitas à decisão de uma autoridade nacional competente".

Sobre o tema, Norma Sueli Padilha pontua que

a avaliação de impacto ambiental já fora adotada na legislação nacional brasileira, como instrumento da Política Nacional do Meio Ambiente, por força da Lei no 6.938, de 31 de agosto de 1981, em seu art. 90, inciso III, bem como pela Resolução CONAMA $1 / 86$ (art. 60, inciso II). Posteriormente, mas ainda em data anterior à RIO/92, a Constituição Federal brasileira de 1988 adotou expressamente o Estudo Prévio de Impacto Ambiental como um dos mais importantes instrumentos para a efetividade do Direito Ambiental, ao determinar que incumbe ao Poder Público "exigir, na forma da lei, para instalação de obra ou atividade potencialmente causadora de significativa degradação do meio ambiente, Estudo Prévio de Impacto Ambiental, a que dará publicidade" (art. 225, §10, inciso IV).

Assim sendo, o toque diferenciador entre os dois princípios acima tratados é o grau de "certeza" (melhor dizendo, probabilidade) com relação ao nexo de causalidade entre uma ação (conduta) e um dano ambiental. Para a instrumentalização do princípio da precaução, basta a suspeita governamental de que a ação pode gerar um determinado dano, enquanto para o da prevenção, a ocorrência da ação gerará, por uma análise dedutiva, de modo quase invariável, o dano a que se pretende evitar.

Consoante demonstrado alhures, a emissão de GEE gera um risco à vida humana (além dos demais seres vivos), à qualidade de vida e ao meio ambiente e, portanto, diante da expressa dicção constitucional, deve ser controlado, pelo Poder Público, a produção e comercialização de bens e produtos que gerem a emissão desses gases. 
SANDRI, Gabriel de Araujo. Imunidade tributária ao crédito de carbono: com base no princípio da prevenção ou precaução. Revista Eletrônica Direito e Política, Programa de Pós-Graduação Stricto Sensu em Ciência Jurídica da UNIVALI, Itajaí, v.10, n.4, $3^{\circ}$ quadrimestre de 2015. Disponível em: www.univali.br/direitoepolitica - ISSN 1980-7791.

Por outro lado, embora também haja uma participação do Poder Público - no caso brasileiro, da Comissão Interministerial de Mudança Global do ClimaCIMGC, que é a Agência Nacional Designada de que trata o Protocolo de Quioto , o mercado de carbono é, em grande parte, uma iniciativa implementada pelo setor privado (instrumentos públicos de mercado ${ }^{21}$ ), que, em razão das benesses que oferta à coletividade, deve ser incentivada pelo Estado.

Traz-se, aqui, os princípios da precaução e o da prevenção para demonstrar que não há saída para se deixar de incentivar a produção de créditos de carbono, pois mesmo que existam alguns céticos - que acreditam que o aumento da concentração de GEE emitidos pelo homem não tem correlação com o aquecimento global -, mesmo assim, pela precaução, deve-se estimular a realização de projetos que visem a redução da emissão de GEE.

Dentre as várias formas de se poder incentivar uma conduta (omissiva ou comissiva) desejável - como é o caso da redução de emissão de GEE -, existe a possibilidade da redução de tributos, que acarreta, por via de consequência, numa redução dos custos, tornando-a mais acessível ao grande mercado, aumentando sua abrangência.

No entanto, a forma mais segura de se desonerar tributos é pela via da imunidade tributária, diante das suas características que Ihes são ínsitas, a serem tratadas a seguir.

\section{IMUNIDADE TRIBUTÁRIA}

Encontra-se dentre os instrumentos da Política Nacional sobre Mudança do Clima a implementação de "medidas fiscais e tributárias destinadas a estimular a redução das emissões e remoção de gases de efeito estufa, incluindo alíquotas diferenciadas, isenções, compensações e incentivos, a serem estabelecidos em lei específica" (art. 60., inc. VI, da Lei no. 12.187/09).

\footnotetext{
${ }^{21}$ Sobre alguns exemplos de instrumentos públicos de mercado, inclusive quanto às críticas a tais modelos neo-liberais, vide BARBIERI, José Carlos. Gestão ambiental empresarial: conceitos, modelos e instrumentos. 3. ed. atual e ampliada. São Paulo: Saraiva, 2011. p. 74-83.
} 
SANDRI, Gabriel de Araujo. Imunidade tributária ao crédito de carbono: com base no princípio da prevenção ou precaução. Revista Eletrônica Direito e Política, Programa de Pós-Graduação Stricto Sensu em Ciência Jurídica da UNIVALI, Itajaí, v.10, n.4, $3^{\circ}$ quadrimestre de 2015. Disponível em: www.univali.br/direitoepolitica - ISSN 1980-7791.

Todos os mecanismos tributários ali inseridos certamente representarão uma redução da carga tributária sobre as operações de redução de GEE. Entretanto, nenhum deles encampa o mesmo grau de proteção do que se houvesse a criação de uma imunidade tributária à receita proveniente da alienação de RCE.

Consoante bastante difundido, as imunidades tributárias são limitações ao poder de tributar, porquanto elencam pessoas, bens e/ou situações (ou operações ${ }^{22}$ ) em que o ente tributante, detentor da competência tributária, está proibido de envolvê-las no aspecto material ou subjetivo/pessoal da norma impositiva-fiscal.

Conforme destacado por Regina Helena Costa, a imunidade tributária encampa uma dúplice natureza: "de um lado, exsurge como norma constitucional demarcatória da competência tributária, por continente de hipótese de intributabilidade, e, de outro, constitui direito público subjetivo das pessoas direta ou indiretamente por ela favorecidas" ${ }^{\prime 23}$. Portanto, a imunidade tributária pode (e deve) ser visto como um direito fundamental do contribuinte ${ }^{24}$, limitador do poder de tributar.

Com efeito, o mesmo documento jurídico que autoriza (legalidade administrativa) os entes estatais a tributar (abrindo-se o campo para a eleição das hipóteses de incidência, atrelado à regra-matriz pertinente), proíbe-os (ou melhor, restringe-Ihes ${ }^{25}$ essa autorização) em determinados casos.

\footnotetext{
22 "[...] Isso quer dizer que, por vezes, [a imunidade tributária] é estabelecida em favor de uma pessoa e, em outros casos, em favor de um bem ou operação" (PAULSEN, Leandro. Curso de direito tributário. 4. ed. rev. atual. e ampl. Porto Alegre: Livraria do Advogado, 2012. p. 98).

${ }^{23}$ COSTA, Regina Helena. Curso de direito tributário: constituição e código tributário nacional. São Paulo: Saraiva, 2009. p. 79.

${ }^{24}$ Daí se poder dizer que a imunidade é uma das formas mais seguras de desoneração fiscal, porquanto uma vez concedidas, ao se tratarem de cláusulas pétreas, não podem ser extirpadas do texto constitucional.

25 Na crítica de Paulo de Barros Carvalho, "inexiste cronologia que justifique a outorga de prerrogativas de inovar a ordem jurídica, pelo exercício de competências tributárias definidas pelo legislador constitucional, para, em momento subseqüente, ser mutilada ou limitada pelo recurso da imunidade. Aliás, a regra que imuniza é uma das múltiplas formas de demarcação de competência" (CARVALHO, Paulo de Barros. Curso de direito tributário. 13. ed. rev. e atual. São Paulo: Saraiva, 2000. p. 166).
} 
SANDRI, Gabriel de Araujo. Imunidade tributária ao crédito de carbono: com base no princípio da prevenção ou precaução. Revista Eletrônica Direito e Política, Programa de Pós-Graduação Stricto Sensu em Ciência Jurídica da UNIVALI, Itajaí, v.10, n.4, 30 quadrimestre de 2015. Disponível em: www.univali.br/direitoepolitica - ISSN 1980-7791.

Não obstante, alguns dizerem que as imunidades tributárias são hipóteses ${ }^{26}$ de não-incidência ${ }^{27}$ constitucionalmente qualificadas ${ }^{28}$, tal definição não pode se esquivar das percucientes e argutas críticas levantadas por Paulo de Barros Carvalho ${ }^{29-30}$, no sentido de que as imunidades são normas de estrutura (atrelada ao esmiuçamento da competência tributária), enquanto as regras de incidência são preceitos de conduta. Em rápidas linhas, poder-se-ia dizer que as imunidades são hipóteses de não-competência ${ }^{31}$, mas não hipóteses de nãoincidência, visto ser atécnico falar em norma cuja incidência (subsunção do conceito fático ao conceito da hipótese eleita) resultaria, paradoxalmente, numa não-incidência - atividade inócua: incidir para não-incidir.

Possui, também, uma íntima relação com os direitos fundamentais, atuando como um notável mecanismo a lhes proteger. Por tais razões, Regina Helena Costa faz referência ao "princípio da não obstância do exercício de direitos fundamentais por via da tributação", visto que

se o ordenamento constitucional ampara determinados direitos, não pode, ao mesmo tempo, compactuar com a obstância ao seu exercício, mediante uma atividade tributante desvirtuada. A atividade tributante do Estado deve conviver harmonicamente com os direitos fundamentais, não podendo conduzir,

\footnotetext{
26 Porque, enquanto normas, habitam o campo abstrato.

27 Porque elegem quais pessoas, bens e situações estão protegidas da imputação fiscal, retirandoas das situações passíveis de incidência (daí a não-incidência).

28 Porque é a Constituição da República, como carta das competências tributárias (e justamente por isso), o único documento hábil a proibir (equivale a dizer: imunizar) a tributação de determinadas pessoas, bens e situações, não sendo tecnicamente possível se falar, pois, em imunidades infraconstitucionais.
}

29 CARVAlHO, Paulo de Barros. Curso de direito tributário. p. 170.

30 "A imunidade tributária é, assim, a qualidade da situação que não pode ser atingida pelo tributo, em razão de norma constitucional que, à vista de alguma especificidade pessoal ou material dessa situação, deixou-a fora do campo sobre que é autorizada a instituição do tributo" (AMARO, Luciano. Direito tributário brasileiro. 13. ed. rev. São Paulo: Saraiva, 2007. p.151); "[...] imunidade tributária como singelas regras que colaboram no desenho do quadro das competências, expostas, todavia, por meio de esquemas sintáticos proibitivos ou vedatórios" (CARVALHO, Paulo de Barros. Curso de direito tributário. p. 168).

31 "Restrições à competência impositiva" (COÊLHO, Sacha Calmon Navarro. Curso de direito tributário brasileiro. 4. ed. São Paulo, 1999. p. 258). 
SANDRI, Gabriel de Araujo. Imunidade tributária ao crédito de carbono: com base no princípio da prevenção ou precaução. Revista Eletrônica Direito e Política, Programa de Pós-Graduação Stricto Sensu em Ciência Jurídica da UNIVALI, Itajaí, v.10, n.4, $3^{\circ}$ quadrimestre de 2015. Disponível em: www.univali.br/direitoepolitica - ISSN 1980-7791.

indiretamente, à indevida restrição ou inviabilização de seu exercício. ${ }^{32}$

Como se vê nessas rápidas linhas, o instituto da imunidade atua como um mecanismo protetor dos caros elementos erigidos pela constituição como direitos fundamentais ou normas estruturantes do Estado (da qual se insere a proteção ao meio ambiente ecologicamente equilibrado), impedindo o seu malferimento pela via da tributação. Indo-se mais além, as imunidades são "cláusulas pétreas", insuprimíveis do texto constitucional.

Nesse ponto, a imunidade tributária pode ser aproveitada para garantir (em razão da impossibilidade de ser revogada) ao crédito de carbono uma desoneração fiscal com status constitucional, impedindo - isto é, retirando a competência do fisco - a tributação da receita proveniente da sua venda, tanto pela via dos impostos (Imposto de Renda, por exemplo), quanto pela das contribuições sociais (PIS, COFINS, CSLL etc.).

Para tanto, bastar-se-ia inserir na constituição uma norma com o seguinte teor: É vedado a União, Estados, Distrito Federal e Municípios instituir e cobrar tributos sobre a receita, faturamento, lucro, serviço ou comércio de operações provenientes da compra ou venda de Redução Certificada de Emissão.

Poder-se-ia, também, estender tal imunidade àqueles que prestam os serviços necessários à obtenção das Reduções Certificadas de Emissões, ampliando-se ainda mais a desoneração para a certificação desses créditos.

Além de proporcionar uma segura redução de custos tributários, o só fato de se inserir expressamente tal tema na constituição trará, naturalmente, um maior holofote ao uso do tributo como mecanismo protetor do meio ambiente e, do mesmo modo, provocará um estudo mais aprofundado sobre o MDL, para o fim de bem entender a extensão dessa imunidade.

${ }^{32}$ COSTA, Regina Helena. Imunidades tributárias: teoria e análise da jurisprudência do STF. 2. ed. rev. e atual. São Paulo: Malheiros, 2006. p. 79. 
SANDRI, Gabriel de Araujo. Imunidade tributária ao crédito de carbono: com base no princípio da prevenção ou precaução. Revista Eletrônica Direito e Política, Programa de Pós-Graduação Stricto Sensu em Ciência Jurídica da UNIVALI, Itajaí, v.10, n.4, $3^{\circ}$ quadrimestre de 2015. Disponível em: www.univali.br/direitoepolitica - ISSN 1980-7791.

Ainda, em razão da alienação de RCE se tratar de uma operação relativamente recente, dita desoneração seria pouco sentida pelo erário público, mas bem recebida por aqueles que a comercializam ou visam comercializá-la.

\section{CONSIDERAÇÕES FINAIS}

O aquecimento global é um dos problemas ambientais transnacionais, fruto da atual sociedade de risco, que mais preocupam a humanidade diante das nefastas consequências advindas de tal fenômeno.

Por se tratar de um problema que se espraia por todo o globo terrestre, a busca por soluções deve necessariamente perpassar por um esforço globalizado, envolvendo todas as nações.

Há um reconhecimento, ainda que não por todos os cientistas, de que o aquecimento global é proveniente do aumento de concentração de GEE, provocados de forma antrópica pelo homem. Portanto, o combate à causa do aquecimento global é um combate à emissão de tais gases.

Todavia, independentemente da existência de prova cabal a demonstrar a íntima correlação entre emissão de GEE e aquecimento global, não se pode aguardar a perfeita comprovação desse liame para se começar a ter atitudes atreladas ao combate dessa causa.

Desse modo, exsurge a necessidade de se prevenir dos riscos provenientes de causas conhecidas (prevenção) e de se precaver daqueles com causas (e efeitos) ainda não-cientificamente comprovados (precaução), porém de existência possível.

Assim, atrai-se a aplicação do princípio da prevenção, porque já há certo consenso, ao menos no âmbito do IPCC, quanto à correlação causal da emissão antrópica de GEE e aquecimento global, e, sobretudo, caso não se visualize essa concordância uniforme de opiniões científicas, evoca-se, então, a utilização do princípio da precaução, pois independentemente da comprovação irrefutável 
SANDRI, Gabriel de Araujo. Imunidade tributária ao crédito de carbono: com base no princípio da prevenção ou precaução. Revista Eletrônica Direito e Política, Programa de Pós-Graduação Stricto Sensu em Ciência Jurídica da UNIVALI, Itajaí, v.10, n.4, $3^{\circ}$ quadrimestre de 2015. Disponível em: www.univali.br/direitoepolitica - ISSN 1980-7791.

dessa relação causa-efeito, deve-se, por precaução, adotar as medidas necessárias para se combater a emissão desses gases.

Nesse ponto, visando estabelecer metas de redução de emissão de GEE e ofertar mecanismos para se alcançar tais objetivos, exsurge no cenário internacional o famigerado Protocolo de Quioto, que dentre esses mecanismos cria o Mecanismo de Desenvolvimento Limpo, ao lado do Comércio de Emissões e da Implementação Conjunta. Contudo, os países em desenvolvimento - caso do Brasil -, por ainda não possuírem metas de redução de emissão de GEE, somente podem participar desse mercado pela via do MDL, com a elaboração de projetos que resultem em Reduções Certificadas de Emissões (os créditos de carbono).

Contudo, diante da burocracia inerente à obtenção das RCE, o custo para a sua emissão se torna bastante elevado, praticamente inviabilizando a elaboração de pequenos (e inúmeros) projetos, o que acaba por desincentivar a proliferação e, por conseguinte, reduz a obtenção de recursos para ajudar na proteção do meio ambiente.

Assim, com o desiderato de buscar reduzir os custos oriundos de tais projetos de MDL, defendeu-se nesse despretensioso trabalho a possibilidade de se inserir na Carta Política uma imunidade tributária à receita proveniente da alienação e produção das RCE, resultando, assim, numa maior abertura para a realização de vários e pequenos projetos, além de colocar no cenário acadêmico, mormente no tributário, o debate sobre os problemas ambientais gerados pelo homem, trazendo uma forçada interdisciplinariedade à referida questão.

\section{REFERÊNCIAS DAS FONTES CITADAS}

AMIRANTE, Domenico. Ambiente e princìpi costituzionali nel diritto comparato. In: AMIRANTE, Domenico (a cura di). Diritto ambientale e costituzione: esperienze europee. Milano: FrancoAngeli, 2010. 
SANDRI, Gabriel de Araujo. Imunidade tributária ao crédito de carbono: com base no princípio da prevenção ou precaução. Revista Eletrônica Direito e Política, Programa de Pós-Graduação Stricto Sensu em Ciência Jurídica da UNIVALI, Itajaí, v.10, n.4, $3^{\circ}$ quadrimestre de 2015. Disponível em: www.univali.br/direitoepolitica - ISSN 1980-7791.

BARBIERI, José Carlos. Gestão ambiental empresarial: conceitos, modelos e instrumentos. 3. ed. atual e ampliada. São Paulo: Saraiva, 2011.

BECK, Ulrich. Liberdade ou capitalismo: Ulrich Beck conversa com Johannes Willms. Trad. Luiz Antôno Oliveira de Araújo.São Paulo: Editora UNESP, 2003.

Sociedade de risco: rumo a uma outra modernidade. Tradução de Sebastião Nascimento; inclui entrevista inédita com o autor. São Paulo: 34, 2010. p.85.

BRASIL. Decreto no. 5.445, de 12 de maio de 2005. Promulga o Protocolo de Quioto à Convenção-Quadro das Nações Unidas sobre Mudança do Clima, aberto a assinaturas na cidade de Quioto, Japão, em 11 de dezembro de 1997, por ocasião da Terceira Conferência das Partes da Convenção-Quadro das Nações Unidas sobre Mudança do Clima. Disponível em:<http://www.planalto.gov.br/ccivil_03/_Ato20042006/2005/Decreto/D5445.htm>. Acessado em 22 dez. 2014.

CARVALHO, Paulo de Barros. Curso de direito tributário. 13. ed. rev. e atual. São Paulo: Saraiva, 2000.

COÊLHO, Sacha Calmon Navarro. Curso de direito tributário brasileiro. 4. ed. São Paulo, 1999.

CORDINI, Giovanni. Dirrito ambientale comparato. 3. ed. Milani: CEDAM, 2002.

COSTA, Regina Helena. Curso de direito tributário: constituição e código tributário nacional. São Paulo: Saraiva, 2009.

COSTA, Regina Helena. Imunidades tributárias: teoria e análise da jurisprudência do STF. 2. ed. rev. e atual. São Paulo: Malheiros, 2006.

FRANGETTO, Flavia Witkowski.; GAZANI, Flavio Rufino. Viabilização jurídica do mecanismo de desenvolvimento limpo (MDL) no Brasil: o Protocolo de Kyoto e a cooperação internacional. Peirópolis: Instituto Internacional de Educação do Brasil (IIEB), 2002. 
SANDRI, Gabriel de Araujo. Imunidade tributária ao crédito de carbono: com base no princípio da prevenção ou precaução. Revista Eletrônica Direito e Política, Programa de Pós-Graduação Stricto Sensu em Ciência Jurídica da UNIVALI, Itajaí, v.10, n.4, $3^{\circ}$ quadrimestre de 2015. Disponível em: www.univali.br/direitoepolitica - ISSN 1980-7791.

LIMIRO, Danielle. Créditos de carbono: Protocolo de Kyoto e projetos de MDL. Curitiba: Juruá, 2009.

LIMIRO, Danielle. Créditos de carbono: Protocolo de Kyoto e projetos de MDL. p. 120 .

MACHADO, Paulo Affonso Leme apud PADILHA, Norma Sueli. Fundamentos constitucionais do direito ambiental. Rio de Janeiro: Elsevier, 2010.

NIVARRA, Luca. Azione inibitoria e principio di precauzione. In: D'ADDA, Alessandro; NICOTRA, Ida Angela; SALANITRO, Ugo (a cura di). Principi europei e illecito ambientale. Torino: G. Giappichelli, 2013.

ONU. Declaração do Rio sobre Meio Ambiente e Desenvolvimento. Disponível em: <http://www.onu.org.br/rio20/img/2012/01/rio92.pdf>. Acesso em 22 dez. 2014.

PANI. Gianguido. Il Protocollo di Kyoto adempimento e sviluppi futuri: normativa strategie tecnologie. San Lazzaro di Savena (Bologna): Zanichelli, 2008.

PAULSEN, Leandro. Curso de direito tributário. 4. ed. rev. atual. e ampl. Porto Alegre: Livraria do Advogado, 2012.

SISTER, Gabriel. Mercado de carbono e Protocolo de Quioto: aspectos negociais e tributação. Rio de Janeiro: Elsevier, 2008.

UNFCC. Status of Ratification. Disponível em <http://unfccc.int /essential_background/convention/status_of_ratification/items/2631.php>. Acesso em 22 dez. 2014.

Submetido em: Agosto/2015

Aprovado em: Novembro/2015 